\title{
Determination of atrazine and propazine metabolites deemed endocrine disruptors in human seminal plasma by LC-ESI-MS/MS
}

Virginia Rodríguez-Robledo ${ }^{1,2^{*}} \mathbb{0}$, Alberto Vendrell1 , Alicia García-Cifuentes ${ }^{1}$, Noemí Villaseca-González ${ }^{1}$ Carmen Guiberteau-Cabanillas², Lydia Luque Martínez ${ }^{3}$, José Julián Garde ${ }^{4}$ and María Rocío Fernández-Santos ${ }^{1,4^{*}}$

\begin{abstract}
Background: The increasing prevalence of male infertility and the declining trend in sperm quality has been associated to compounds known as "endocrine-disruptors". The proven endocrine-disrupting effects of atrazine and propazine herbicides led us to conduct long-term research based on highly accurate specific analytical methods with a view to confirming the suspected association. Among the proposed developments was a sensitive analytical method for the simultaneous determination of three metabolites of atrazine and propazine.

Results: In this work, the method was for first time used for the chromatographic separation and determination of deethyl- and deisopropyl-atrazine (DEA and DIA, respectively) and propazine-2-hydroxy (PP-2OH) in human seminal plasma by LC-ESI-MS/MS using deuterated atrazine (d5-AT) as internal standard (IS). Chromatographic and mass spectrometric conditions such as the mobile phase composition and flow-rate, injected volume, dry gas source temperature and flow-rate, nebulizer pressure and capillary voltage were all carefully optimized. Analytes were identified and quantified by using the multiple reaction monitoring (MRM) mode as applied to positive ions $\left([\mathrm{M}+\mathrm{H}]^{+}\right)$. Transitions at three different $\mathrm{m} / \mathrm{z}$ values for each analyte were selected from precursor ions, and the $212.1 \rightarrow[128]^{+}$, $188.1 \rightarrow[146]^{+}$and $174.1 \rightarrow[68.1]^{+}$transitions for PP-2OH, DEA and DIA, respectively, were found to be quantitative. The proposed method was validated in terms of precision (repeatability and reproducibility), linear range $\left(10-240 \mathrm{ng} \mathrm{mL}^{-1}\right)$, limit of detection $\left(150-210 \mathrm{pg} \mathrm{mL}^{-1}\right)$, and quantification $\left(500-700 \mathrm{pg} \mathrm{mL}^{-1}\right)$, recovery, accuracy and matrix effects on extracts from variably treated seminal plasma samples. The overall analytical method was successfully applied to human seminal plasma samples from volunteers. PP-2OH was found at concentrations from 1.10 to $11.3 \mathrm{ng} \mathrm{mL}^{-1}$ in four of the six samples, and so was DIA at $9.60 \mathrm{ng} \mathrm{mL}^{-1}$ in one.

Conclusions: These results are suggestive of bioaccumulation of the target analytes in humans. Untargeted analytes including suspected parent molecules (atrazine and propazine) and other ions [viz., deethyldeisopropyl-atrazine (DD) and diamino-s-chlorotriazine (DACT)] were also detected under the working conditions used. These results may open up new prospects for as yet very incipient research into the bioaccumulation of endocrine disruptors in seminal plasma.
\end{abstract}

Keywords: Endocrine disruptors, s-Triazine metabolites, LC/ESI-MS/MS, Male infertility, Human seminal plasma

\footnotetext{
*Correspondence: virginia.rrobledo@uclm.es; mrocio.fernandez@uclm.es

${ }^{1}$ Faculty of Pharmacy, Regional Center for Biomedical Research,

University of Castilla-La Mancha, Albacete, Spain

Full list of author information is available at the end of the article
} 


\section{Graphical Abstract}

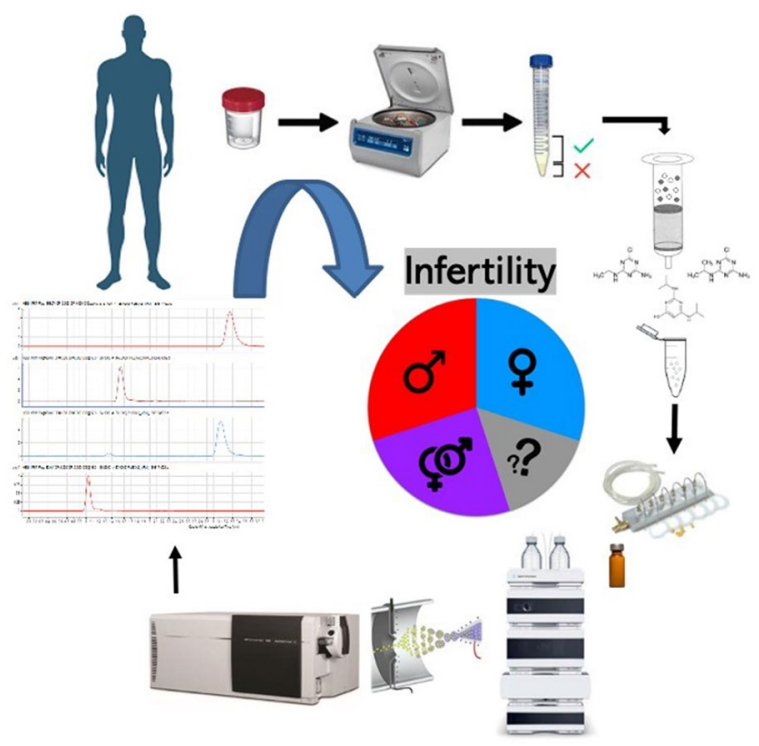

\section{Introduction}

Defective sperm function can arise from a wide range of primary genetic, lifestyle and environmental factors acting alone or, more frequently, in combination. Recently, Selvaraju et al. (2020) reviewed the effects of environmental contaminants on male reproductive function and their potential mechanisms of action. They concluded that environmental contaminants, which are typically chemicals, have deleterious effects on male reproduction [1]. According to the United States Environmental Protection Agency (US-EPA), an endocrine disrupting chemical (EDC) is "an exogenous agent that interferes with synthesis, secretion, transport, metabolism, binding action, or elimination of natural blood-borne hormones that are present in the body and are responsible for homeostasis, reproduction, and developmental process" [2, 3]. EDCs, which have been deemed a global threat to public health by the World Health Organization (WHO), are arousing increasing interest [4]. These compounds are highly heterogeneous in nature and have been classified according a number of factors [2] including physicochemical properties, environmental persistence and bioaccumulation in humans [5]. The production and use of various chemicals as additives in agriculture has grown substantially in recent decades. Some such chemicals can have harmful effects on health, so their release and/ or accumulation in the environment or in food chains is a cause for concern. Among those harmful chemicals are triazine pesticides, a family of organic compounds differing in the substituents on the triazine ring.
s-Triazines (particularly atrazine, simazine and propazine) are used worldwide as selective pre- and post-emergence herbicides for weed control on many agricultural crops such as corn, wheat and barley, as well as on railways, roadsides and golf courses [6]. Atrazine is the second most widely used herbicide in agriculture [7] after glyphosate, while propazine is used mainly as an herbicide for indoor greenhouse plants, and also to control broadleaf and grassy weeds on sorghum [8].

Agriculturally used triazines can undergo biotic and non-biotic degradation through de-alkylation of amine groups at positions 4 and 6 on the triazine ring, dechlorination, de-amination or hydrolysis of the substituent at 2 [9], and to a lesser extent, even ring cleavage [10-13], to variety of derivatives. Atrazine, propazine and also their derivatives can accumulate in soil and contaminate ground and surface water as a result. In this way, they can reach various organisms and have mutagenic, teratogenic or endocrine disrupting effects on them [14]. Also, they can reach the human body through consumption of contaminated food or water, or exposure to aerosols-which can enter the respiratory tract or be absorbed through the skin [15].

Physiologically, heavy exposure to these herbicides can alter hepatic microsomal metabolism to a variable extent depending on the particular species [16]. However, no metabolic or pharmacokinetic studies on atrazine or propazine in humans, the potentials effects of the parent compounds or their metabolites on living organisms, or their bioaccumulation, have been conducted to date. 
In fact, only a few studies have explored the metabolism of atrazine and propazine in vitro or in vivo. Atrazine is metabolized primarily by cytochrome P450s (CYPs) and, to a lesser extent, by glutathione transferases (GSTs) [16-18]. The major CYP-derived metabolites of atrazine are deethylatrazine (DEA) and deisopropylatrazine (DIA). Both are metabolized to diamino-s-chlorotriazine (DACT) $[8,19]$, which is the major atrazine metabolite detected in vivo in rats [20]; however, the enzyme effecting its formation remains unknown $[16,21]$. Between 8-12 metabolites of atrazine conjugated [22] via glutathione s-transferases [23] have been identified in urinary metabolites profile [24].

In 2016, US EPA deemed the chlorometabolites DIA, DEA and deethyldeisopropyl atrazine (DD) toxicologically equipotent to the parent triazines, but considered the conjugated derivatives toxicologically inactive metabolites [8]. The metabolism of propazine has scarcely been examined in vivo or in vitro $[16,18]$. Hanioka et al. (1999) detected no $\mathrm{N}$-bidealkylation or 2-hydroxylation metabolites in any of the previous systems. However, propazine 2-hydroxy (PP-2OH), which is similarly toxic to the parent triazine, has been identified among the degradation products formed in the natural environment [9]. Because it is hardly metabolized under physiological conditions, PP-2OH may be an effective marker for bioaccumulation. Owing to their biological activity and high mobility, triazine pesticides have aroused great environmental concern for many years $[25,26]$. Some studies have focused on the detection of s-triazine herbicides in diverse environments [13] by examining atrazine and its major transformation products in waters and soils, mainly [13, 25, $27,28]$. Their presence in biological samples has been less frequently studied [29], and mainly in urine and plasma [20, 24], even though fluids such as semen and seminal plasma can contain highly useful information about bioaccumulation of pollutants [30] potentially associated to male infertility [31-33].

Seminal plasma represents $95 \%$ of human semen, which includes secretions from accessory sex glands and plays a key role in natural fertilization as it contributes to timely capacitation, acrosome reaction and spermoocyte interaction [34]. Its complex proteomic composition, and growth and transcription factors, provide a safe environment for spermatozoa; also, ejaculated semen serves as a vehicle for spermatozoa to the female genital tract. Human seminal plasma is a rich source of potential biomarkers for male infertility and reproduction disorders [32]. Exposure to some drugs, toxins or pollutants can affect seminal plasma and alter sperm function even after ejaculation [14], and molecular alterations may contribute to male infertility [35]. Information on the metabolome of healthy human semen is rather scant, however
[36]. For example, propazine has scarcely been examined in this respect, and the effects of atrazine on sperm have been studied to a limited extent only. As found in other studies, atrazine can behave as an anti-androgen, xenoestrogen and oestrogen agonist [37]. Epidemiological studies conducted in USA have revealed sperm concentration and motility to be reduced by atrazine exposure in humans [38]. Based on the foregoing, s-triazines can have a deleterious impact on human reproductive health.

Although the analysis of compounds present in complex biological matrices such as seminal plasma is challenging, recent advances have enabled the identification of toxins and pharmaceuticals such as nicotine [39] elvitegravir [40] and tadalafil [41], and endocrine disruptors (bisphenol A [42-44] and phthalates [45], mainly), in seminal plasma. To our knowledge, however, no determinations of triazine compounds and/or their metabolites in human semen or seminal plasma have been reported to date. The scarcity of pharmacokinetic and metabolic information on triazines such as atrazine and propazine, and the potential oestrogenic activity of some metabolites (DIA and DEA) and degradation products (PP-2OH) according EPA [46], could be expanded by developing an effective analytical method for their determination in human seminal plasma. In this work, we developed the first accurate, sensitive, selective method for the simultaneous determination of two active intermediate metabolites of atrazine (DIA and DEA), and the degradation product of propazine $\mathrm{PP}-2 \mathrm{OH}$, which US EPA has deemed endocrine disruptors. Under the optimum conditions established here, the proposed method, which uses liquid chromatography coupled to mass spectrometry detection (MSD) via an electrospray ionization interface (LC-ESI/MS), allowed the unequivocal identification and accurate quantification of the target analytes in seminal plasma. The samples were previously subjected to enzymatic hydrolysis $(\mathrm{EH})$ and solid-phase extraction (SPE) in order to isolate the analytes, clean-up and preconcentrate the final extract.

\section{Materials and methods \\ Chemicals}

The atrazine and propazine metabolites 2-OH-propazine (99.0\% pure), deethyl and deisopropyl atrazine ( $97.5 \%$ and 99.5\%, respectively) were purchased from Dr Ehrenstorfer $\mathrm{GmbH}$ (Augsburg, Germany) and stored at $-20{ }^{\circ} \mathrm{C}$. Five times deuterated (d5)-atrazine [viz., 6-chloro-2- $N$ (1,1,2,2,2-pentadeuteredethyl)-4- $N$-propan-2-il-1,3,5-triazine-2,4-diamine) from Sigma-Aldrich (St. Louis, MO, USA) was used as internal standard (IS). Acetonitrile and methanol in HPLC grade were purchased from Honeywell Research Chemicals Riedel-de Häen (Seelze, Germany) and ethanol (analytical-grade) was obtained from 
Panreac (Barcelona, Spain). Acetic and phosphoric acid $99 \%$ and $85 \%$ pure, respectively, were supplied by VWR International Eurolab and Scharlab (Barcelona, Spain), respectively. The enzyme (type HP2 $\beta$-glucuronidase, $116300 \mathrm{IU} \mathrm{mL}^{-1}$ ) was obtained from Sigma-Aldrich (St. Louis, MO, USA).

All solutions were prepared in de-ionized water (18.2 $\mathrm{m} \Omega \mathrm{cm}^{-1}$ ) from a Milli-Q apparatus (Millipore Ibérica S.A., Madrid, Spain), and high-purity, zero-grade nitrogen was used for the ESI source and detector (triple quadrupole).

\section{Standard and stock solutions}

A known amount of each analyte was dissolved in $50 \mathrm{~mL}$ of ethanol to a final concentration of $1008 \mu \mathrm{g} \mathrm{mL} L^{-1}$ for DIA, and $1000 \mu \mathrm{g} \mathrm{mL}^{-1}$ for DEA and PP-2OH. All stock solutions were stored at $-20{ }^{\circ} \mathrm{C}$. Medium solutions of each individual compound (IS included) at a $50 \mu \mathrm{g} \mathrm{mL}^{-1}$ concentration were prepared in ethanol and stored at $4-8{ }^{\circ} \mathrm{C}$ in the dark. Finally, working mixed solutions were prepared by diluting the medium-solutions to a concentration of $500 \mathrm{ng} \mathrm{mL}^{-1}$ in mobile phase (a 85:15 v/v mixture of $0.1 \%$ acetic acid and acetonitrile) and stored at $4-8{ }^{\circ} \mathrm{C}$. The working solutions were used in all validation tests irrespective of matrix type.

\section{Biological samples: collection, storage and treatment Collection of sperm and storage of seminal plasma}

Human sperm was obtained from six healthy sperm donors selected according to ESHRE guidelines for gamete donation of the Bernabeu Institute (Albacete, Spain). Samples were collected after $48-72 \mathrm{~h}$ of abstinence and handled according to the WHO's 2010 guidelines. Seminal plasma was extracted by centrifuging the ejaculates at $12.000 \times g$ at $4{ }^{\circ} \mathrm{C}$ for $20 \mathrm{~min}$. The resulting supernatants were stored at $-20{ }^{\circ} \mathrm{C}$ until they were further used following re-centrifugation under the same conditions.
Ovine sperm for validation purposes was obtained from three adult rams of the Manchega breed aged 3 years or more reared on the farm of the University of Castilla-La Mancha. Semen was collected by using an artificial vagina and seminal plasma extracted by centrifuging the ejaculates al $12.000 \times g$ at $4{ }^{\circ} \mathrm{C}$ for $20 \mathrm{~min}$. The resulting supernatants were stored at $-20{ }^{\circ} \mathrm{C}$ until they were further used following re-centrifugation under the same conditions. All animal procedures were performed in accordance with Spanish Animal Protection Regulation RD53/2013, which conforms to European Union Regulation 2010/63/UE.

\section{Sample treatment}

Stored seminal plasma samples were treated according to previously established protocols. Briefly, a volume $500 \mu \mathrm{L}$ of seminal plasma was centrifuged at $16,000 \times g$ at $4{ }^{\circ} \mathrm{C}$ for $10 \mathrm{~min}$ and subsequently subjected to enzymatic hydrolysis. For this purpose, $5 \mu \mathrm{L}$ of $\beta$-glucuronidase and a known amount of IS (d5-AT) were added to centrifuged plasma, which was then vortexed for $2 \mathrm{~min}$ and incubated at $37^{\circ} \mathrm{C}$ for $12 \mathrm{~h}$. Then, a supernatant volume was further vortexed and re-centrifuged under the same conditions. Isolation and preconcentration were done by using a Manifold Visiprep ${ }^{\mathrm{TM}}$ solid-phase extractor (SPE) from Sep-Pack (Madrid, Spain) coupled to an XF 54 23050 vacuum pump from Millipore. The SPE process was conducted with Sep-Pack Plus Bond Elut C18 cartridges (200 mg, $3 \mathrm{~mL}, 50 / \mathrm{pk}$ ) from Waters (Milford, CT, USA). The extraction-preconcentration procedure involved the following steps: (1) conditioning of the cartridge by washing with $2.0 \mathrm{~mL}$ of methanol and $2.0 \mathrm{~mL}$ of de-ionized water; (2) loading of organic extract $(500 \mu \mathrm{L})$ at $0.5 \mathrm{~mL} \mathrm{~min} \mathrm{~min}^{-1}$; (3) drying of the cartridge for $2 \mathrm{~min}$; (4) washing with $2.0 \mathrm{~mL}$ of de-ionized water three times to minimize interferences from the seminal plasma matrix;

Table 1 Chemical features, response to electrospray ionization and chromatographic retention time for each metabolite

\begin{tabular}{|c|c|c|c|c|c|c|}
\hline Metabolite (abbreviated name) & $\begin{array}{l}\text { Molecular weight (mw) (g } \\
\mathrm{mol}^{-1} \text { ) molecular formula }\end{array}$ & $\begin{array}{l}\text { Precursor ion } \\
{[\mathrm{M}+\mathrm{H}]^{+}} \\
\mathrm{m} / \mathbf{z}\end{array}$ & $\begin{array}{l}\text { Fragmentor } \\
\text { voltage (V) }\end{array}$ & $\begin{array}{l}\text { Product ion } \\
{[\mathrm{M}+\mathrm{H}]^{+} \mathrm{m} / \mathrm{z}} \\
\text { Quantitative } \\
\text { qualitative }\end{array}$ & $\begin{array}{l}\text { Collision } \\
\text { energy }(\mathrm{eV})\end{array}$ & $\begin{array}{l}\text { Retention } \\
\text { time (RT, } \\
\text { min) }\end{array}$ \\
\hline Propazine-2-hydroxy (PP-2OH) & $\begin{array}{l}211.14 \\
\mathrm{C}_{9} \mathrm{H}_{17} \mathrm{ON}_{5}\end{array}$ & 212.15 & 166 & $\begin{array}{l}128.0^{*} \\
86.1 \\
170.1\end{array}$ & $\begin{array}{l}20 \\
32 \\
16\end{array}$ & 2.8 \\
\hline Deisopropylatrazine (DIA) & $\begin{array}{l}173.05 \\
\mathrm{C}_{5} \mathrm{H}_{8} \mathrm{~N}_{5} \mathrm{Cl}\end{array}$ & 174.06 & 98 & $\begin{array}{l}68.1^{*} \\
96.1 \\
62.1\end{array}$ & $\begin{array}{l}32 \\
20 \\
56\end{array}$ & 2.4 \\
\hline Deethylatrazine (DEA) & $\begin{array}{l}187.06 \\
\mathrm{C}_{6} \mathrm{H}_{10} \mathrm{~N}_{5} \mathrm{Cl}\end{array}$ & 188.07 & 98 & $\begin{array}{l}146.0^{*} \\
79.0 \\
68.1\end{array}$ & $\begin{array}{l}16 \\
28 \\
32\end{array}$ & 3.8 \\
\hline
\end{tabular}


(5) drying for 5 min and (6) elution of the analytes with $4.0 \mathrm{~mL}$ of an 80:20 v/v acetonitrile:methanol mixture three times. The eluate thus obtained was transferred into 5.0-mL conical glass vessels and the organic extract evaporated with nitrogen gas for dissolution in $100 \mu \mathrm{L}$ of mobile phase and injection into the LC/ESI-MS/MS system.

\section{Liquid chromatography and mass spectrometry conditions} Analytes were separated on an Agilent 1260 Infinity HPLC system equipped with a binary pump and a vacuum degasser. Samples were injected with an Agilent autosampler furnished with a needle of $25 \mu \mathrm{L}$ and analysed on a model 6460 triple quadrupole mass spectrometer from Agilent Technologies (Santa Clara, CA, USA) equipped with an ESI interface. Zero-grade nitrogen was supplied by a nitrogen generator from PEAK Scientific (Chicago, IL, USA) and high-purity hydrogen was obtained from Linde (Valencia, Spain).

Analytes were separated by gradient elution at $0.3 \mathrm{~mL} \mathrm{~min}{ }^{-1}$ from a Zorbax SB-Aq column $(2.1 \times 100 \mathrm{~mm}, 1.8 \mu \mathrm{m})$ at $25{ }^{\circ} \mathrm{C}$. The mobile phase was a $85: 15 \mathrm{v} / \mathrm{v}$ mixture of $0.1 \%$ acetic acid (A) and acetonitrile (B). The elution programme was as follows: $15 \% \mathrm{~B}$ for $4 \mathrm{~min}, 85 \% \mathrm{~B}$ in $1 \mathrm{~min}$ for $4 \mathrm{~min}$ and back to $15 \% \mathrm{~B}$ in $1 \mathrm{~min}$ holding $5 \mathrm{~min}$. The injected volumes of standard and sample were always $10 \mu \mathrm{L}$.

The optimum operating conditions for the ESI source were a dry gas temperature of $300{ }^{\circ} \mathrm{C}$, a gas flow-rate of $11 \mathrm{~L} \mathrm{~min}^{-1}$, a nebulizer pressure of 15 p.s.i, a capillary voltage of $4000 \mathrm{~V}$ and a chamber/corona current of 0.26 $\mu \mathrm{A}$. Analytes were detected and quantified by applying the Multiple Reaction Monitoring (MRM) mode to positive ions to acquire at least three transitions for each metabolite (see Table 1), the most abundant transition of the three being used for quantitative analysis and the other two for qualitative analysis.

\section{Validation}

The reliability of the proposed method for determining male infertility-related metabolites was established by using triplicate injections to assess signal intensity, relative peak area (RPA) and signal-to-noise $(\mathrm{S} / \mathrm{N})$ ratio. Also, analytical performance-related parameters such as precision, limit of detection (LOD), limit of quantitation (LOQ) and linearity were assessed in bio-extracts from spiked blank samples treated as described in "Biological samples: collection, storage and treatment" Section (sample treatment).

\section{Results and discussion}

\section{Development of the analytical method}

The operational chromatographic and mass spectrometry conditions were adjusted for optimal separation and determination of the analytes and maximization of chromatographic peaks and analytical signals (abundance and stability).

\section{Preliminary studies}

The chromatographic conditions for the simultaneous separation of DIA, DEA, PP-2OH and the internal standard (deuterated atrazine, d5-AT) were established in preliminary tests. The initially selected chromatographic conditions were as follows: the reverse mode; a C18 column $100 \mathrm{~mm}$ long $\times 2.1 \mathrm{~mm}$ i.d. packed with particles $1.8 \mu \mathrm{m}$ in diameter as stationary phase; and isocratic elution with a mobile phase consisting of a 70:30 v/v mixture of $0.1 \%$ formic acid and methanol. These conditions resulted in split and rather broad chromatographic peaks, a low efficacy $(N)$ and poor resolution $\left(R_{S}\right)$ between peaks.

Because the target metabolites were highly polar (see their chemical structures in Fig. 1), they had a low affinity for the stationary phase and were thus weakly retained on it. This led us to increase the proportion of aqueous phase in order to delay elution of the analytes for increased contact with the stationary phase of the column in order to facilitate their chromatographic separation. We thus considered other stationary phases allowing higher proportions of aqueous component to be used in the mobile phase. For this purpose, we replaced conventional C18 column previously used, with a $100 \mathrm{~mm}$ long $\times 2.1 \mathrm{~mm}$ i.d. Zorbax SB-Aq column packed with particles $1.8 \mu \mathrm{m}$ in diameter. This column is chemically similar to a C18 column and can operate in the reverse mode, but allows a very low proportion or even no organic component to be used for elution. As a result, it provided better peak shapes and higher efficiency throughout. Peak shape, and hence separation between peaks, was improved by increasing the proportion of water in the mobile phase. This, however, diminished peak height and $\mathrm{S} / \mathrm{N}$ ratio or even led to no signal being obtained with high proportions of water, which led us to consider other types of mobile phase and alternative conditions.

\section{Optimization of $L C$ conditions}

The chromatographic variables composition, elution mode and mobile phase flow-rate were adjusted for optimal signal strength, and peak shape and separation. The procedure was as follows: 
Propazine-2-hydroxy (PP-2OH):

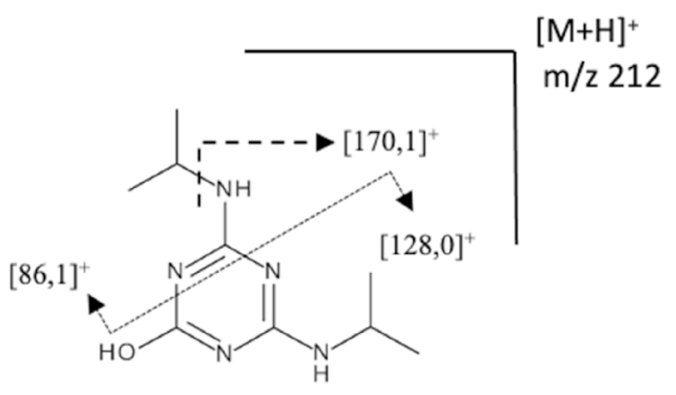

Deisopropylatrazine (DIA):

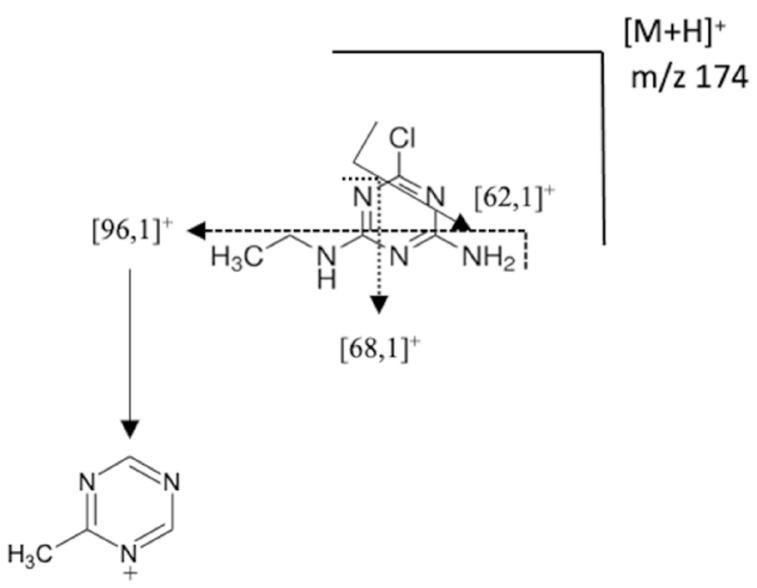

Deethylatrazine (DEA):

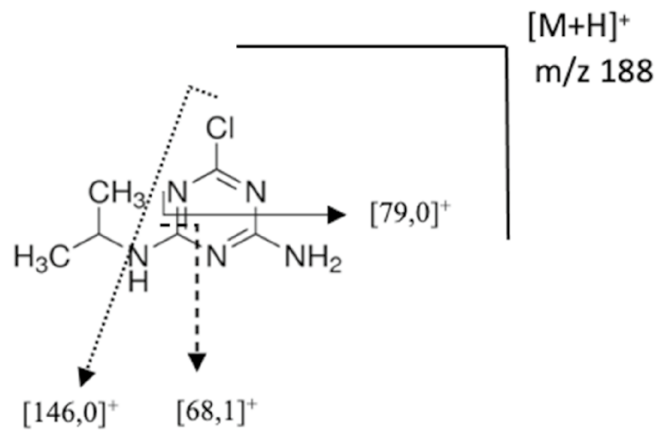

Fig. 1 MS fragmentation precursor ion for each metabolites

(a) Because formic acid does not affect ionization, it was removed from the organic phase and replaced with acetic acid in the same proportion in the aqueous phase. (b) Methanol was replaced with acetonitrile as organic solvent in the mobile phase, which substantially improved peak shape and signal stability. 


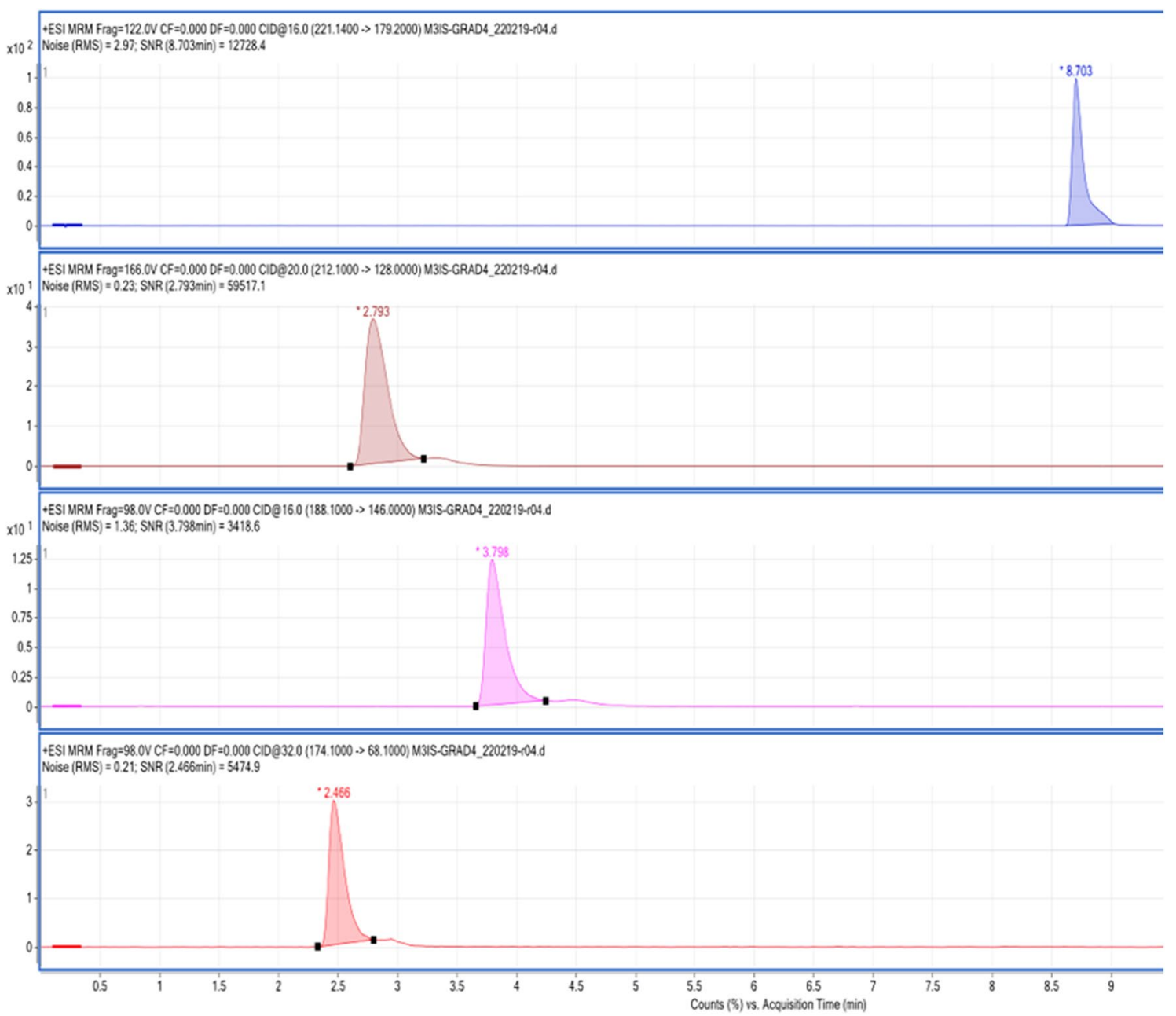

Fig. 2 Extracted ion chromatograms for atrazine and propazine metabolites as obtained under selected instrumental conditions as MRM window: $1^{\circ}$ ) internal standard (d5-atrazine); 20) PP-2OH (propazine metabolite); $3^{\circ}$ ) DIA and 4º) DEA (atrazine metabolites)

(c) Mobile phases containing $0.1 \%$ acetic acid:acetonitrile ranged between 70 and $100 \%$ acetic acid were used in the isocratic and gradient modes.

With isocratic elution, an 85:15 v/v acetic acid (A)-acetonitrile (B) mobile phase provided acceptable resolution among analytes, albeit with an overall analysis time longer than $25 \mathrm{~min}$ owing to the IS. Tests were therefore repeated in the gradient mode, using variable proportions of acetic acid in the mobile phase to reduce analysis times, and improve chromatographic separation and peak shape.

The most effective elution gradient was using an initial mobile phase composition of 85:15 (A:B v/v) for $4 \mathrm{~min}$, reducing the proportion of acetic acid from 85 to $15 \%$ in $1 \mathrm{~min}$ keeping for $4 \mathrm{~min}$ and then back to the initial conditions $(85: 15 \mathrm{v} / \mathrm{v})$ in $1 \mathrm{~min}$ for $5 \mathrm{~min}$ to decrease the IS retention time (RT). Under these conditions, the three metabolites and the IS were separated within $10 \mathrm{~min}$ (Fig. 2).

None of the other chromatographic variables studied (viz., mobile phase flow-rate, column temperature and injected volume) had a critical effect on the analyte separation efficiency. The influence of the mobile phase flow-rate and column temperature was examined over the ranges $0.2-0.6 \mathrm{~mL} \mathrm{~min}^{-1}$ and $20-40{ }^{\circ} \mathrm{C}$, respectively. A flow-rate of $0.3 \mathrm{~mL} \mathrm{~min}{ }^{-1}$ and a temperature $25{ }^{\circ} \mathrm{C}$ were deemed optimal in terms of peak shape, efficiency and retention time for the three analytes. With biological samples, however, it is essential to use an optimal injected volume as well. An increased injected volume (i.e. an increased amount of sample) is expected to introduce greater amounts of biological components into the system-and hence to result in stronger interferences of the biological matrix with the column leading to impaired analyte separation. By contrast, very low 
injected volumes led to scarcely reproducible results subject to large errors. The influence of the injected volume was examined over the range $5-20 \mu \mathrm{L}$ and $10 \mu \mathrm{L}$ selected as the best trade-off between sensitivity and reproducibility.

\section{Optimization of MS/MS parameters}

The main purpose of optimizing the MS/MS variables was ensuring stable, reproducible, selective signals. To this end, the influence of ionization-related parameters such as nebulizer flow-rate, temperature and pressure, and that of other variables such as precursor ion, product and transitions were also examined.

Firstly, we selected the best precursor ion to characterize each analyte from the most abundant ions detected in the full-scan mode. Specific precursor ion-related variables such as transitions, fragmentor voltage $(\mathrm{V})$ and collision energy $(\mathrm{eV})$ were automatically proposed by using the Optimizer function in the software MassHunter from Agilent. At least three transitions from the precursor to the product ions must be selected to ensure accurate quantification and unambiguous identification of each compound.

The assignment of product ion from precursor ion mass of PP-2OH, DEA and DIA is given in Fig. 1. The highest transitions of each precursor ion are used for quantification and the remainder for qualitative identification. In all analytes, ionization was more stable and sensitive in the positive ion mode $\left([\mathrm{M}+\mathrm{H}]^{+}\right)$than it was in the negative mode $\left([\mathrm{M}-\mathrm{H}]^{-}\right)$. The $m / z$ values for the transitions of each compound, and their collision energies, were as follows:

(a) PP-2OH. $[\mathrm{M}+\mathrm{H}]^{+}=212.1 \rightarrow[170.1]^{+}, 16 \mathrm{eV}$; $[212.1]^{+} \rightarrow[128.0]^{+}, 20 \mathrm{eV}$; and $[212.1]^{+} \rightarrow[86.1]^{+}$, $32 \mathrm{eV}$. Fragmentor $=166 \mathrm{~V}$.

(b) DEA. $\quad[\mathrm{M}+\mathrm{H}]^{+} \quad=188.1 \rightarrow[146]^{+}, \quad 16 \mathrm{eV}$; $[188.1]^{+} \rightarrow[79.0]^{+}, 28 \mathrm{eV}$; and $[188.1]^{+} \rightarrow[68.1]^{+}$, $32 \mathrm{eV}$. Fragmentor $=98 \mathrm{~V}$.

(c) DIA. $[\mathrm{M}+\mathrm{H}]^{+} \quad=174.1 \rightarrow 96.1, \quad 20 \mathrm{eV}$; $[174.1]^{+} \rightarrow[68.1]^{+}, 32 \mathrm{eV}$; and $[174.1]^{+} \rightarrow[62.1]^{+}$, $56 \mathrm{eV}$. Fragmentor $=98 \mathrm{~V}$.

Table 1 shows the chemical structure, formula, molecular weight, characteristic transitions, collision energy, fragmentor value and retention time for each analyte.

Related operational variables such as dry gas flowrate, gas temperature and nebulizer pressure have a direct impact on the ionization process and were thus also examined over the ranges afforded by the equipment, namely: $5-13 \mathrm{~L} \mathrm{~min}^{-1}, 250-350^{\circ} \mathrm{C}$ and $10-60$ p.s.i. A flow-rate of $11 \mathrm{~L} \mathrm{~min}^{-1}$, a temperature of $300{ }^{\circ} \mathrm{C}$ and a pressure of 15 p.s.i were selected as optimal as they provided the highest RPA, stable signals and the highest possible $\mathrm{S} / \mathrm{N}$ ratio. A capillary voltage of $4000 \mathrm{~V}$ and chamber/corona current of $0.26 \mu \mathrm{A}$ were also used.

Analytes were detected and later quantified by using positive ion polarity in the multiple reaction monitoring (MRM) mode in addition to the total ion chromatogram (TIC) obtained in the full scan and the combination of selected transitions, respectively, for each compound.

\section{Validation of the proposed method}

The proposed method was validated by confirming that it fulfilled the requirements for which it was developed and provided the results expected from it. For this purpose, the method was assessed in terms of precision, LOD and LOQ, response linearity, recoveries and matrix effects by using bio-extracts from ovine seminal plasma. Specifically, a pooled sample $(n=3)$ of previously analysed ram seminal plasma was used as a blank matrix for validation.

Treatment of biological samples: recovery and matrix effects The general procedure for extraction of biological samples can include the following steps: (a) optional protein denaturation, protein precipitation or deproteination; (b) extraction or isolation by liquid-liquid extraction (LLE), solid-phase extraction (SPE), dilution, shooting, etc.; and (c) preconcentration (optional) and reconstitution. Each step in the previous, provenly effective process is intended to facilitate complete extraction of analytes from biological samples. Based on previous work [21, $34]$, and on the specific type of biological sample used (seminal plasma), we examined the effectiveness of various sample treatments after SPE, namely: (a) enzymatic hydrolysis (EH); (b) acid hydrolysis (AH) and (c) protein precipitation (PP) with an organic solvent. All were performed in two steps different in purpose. Thus, EH, $\mathrm{AH}$ and PP were intended to remove the largest possible amounts of interferents from the samples in order to reduce matrix effects; on the other hand, SPE was used to facilitate isolation and preconcentration of the target analytes.

The previous treatments were used to assessed for performance by using working-strength standards and seminal plasma blanks (viz., samples containing no detectable concentrations of the analytes). The latter samples were spiked with the analytes at the beginning of each treatment or after extraction in order to determine recoveries and matrix effects, respectively. The seminal plasma samples were first defrosted at room temperature to obtain $500 \mu \mathrm{L}$ aliquots that were centrifuged at $16.000 \times g$ at $4{ }^{\circ} \mathrm{C}$ for $10 \mathrm{~min}$. The influence of the experimental variables (viz., nature and volume of the organic and aqueous solvents used in the washing steps, sample volume, eluted volume and final extract 
volume, among others) was examined after each step of the SPE process. The high complexity of the seminal plasma matrix, where the analytes were present at very low levels, required using SPE for preconcentration and clean-up in addition to separation.

The procedure for each analyte was as follows:

- EH-SPE. A volume of $5 \mu \mathrm{L}$ of $\beta$-glucuronidase solution was added to the supernatant, vortexed for 2 min and incubated at $37^{\circ} \mathrm{C}$ for $12 \mathrm{~h}$. SPE was done with Bond Elut ${ }^{\mathrm{TM}} \mathrm{C} 18$ SPE $(200 \mathrm{mg}, 3 \mathrm{~mL})$, the reversed-phase sorbent being previously conditioned by passing $2.0 \mathrm{~mL}$ of methanol and $2.0 \mathrm{~mL}$ of de-ionized water. Then, each incubated sample (approximately $500 \mu \mathrm{L}$ ) was slowly loaded onto the cartridge at flow-rate of $0.5 \mathrm{~mL} \mathrm{~min}^{-1}$, the cartridge being washed at $1.0 \mathrm{~mL} \mathrm{~min}^{-1}$ with $2.0 \mathrm{~mL}$ of water three times. Next, the metabolites were eluted with $4 \mathrm{~mL}$ of $80: 20 \mathrm{v} / \mathrm{v}$ acetonitrile:methanol and the eluates dried under a stream of nitrogen. The final residue was redissolved in $100 \mu \mathrm{L}$ of previously used mobile phase for injection into the LC-MS equipment.

- AH-SPE. The supernatant obtained by centrifugation (around $500 \mu \mathrm{L}$ ) was given up to $2.0 \mathrm{~mL}$ of $5 \%$ phosphoric acid and subjected to SPE like the previ- ous analyte but using an appropriate initial volume of sample. Also, the final residue was redissolved in mobile phase and injected into the LC-MS equipment.

- PP-SPE. A 250- $\mu \mathrm{L}$ aliquot of the supernatant obtained by centrifugation was supplied with an identical volume of ethanol and centrifuged under the same conditions as the previous analytes for 10 min. Then, the analytes were isolated by using an appropriate volume in each SPE step. The resulting residue was redissolved in mobile phase for injection into the LC-MS equipment.

Analyte recovery with the EH-SPE treatment was 89.2\% for PP-2OH, $90.9 \%$ for DEA and $92.1 \%$ for DIA by contrast, recoveries with AH-SPE and PP-SPE were all less than $50 \%$. Comparing RPA between samples spiked after extraction and those for working-strength standards of identical concentration allowed us to estimate matrix effects, which were deemed not significant when the difference from the normalized value for each analyte was less than $10 \%$. The differences were $15-18 \%$ with the EHSPE treatment and $28-43 \%$ with the others.

Based on the previous results, the EH-SPE treatment was the best choice as it provided recoveries about of 90\% with relative standard deviations (RSD) less than

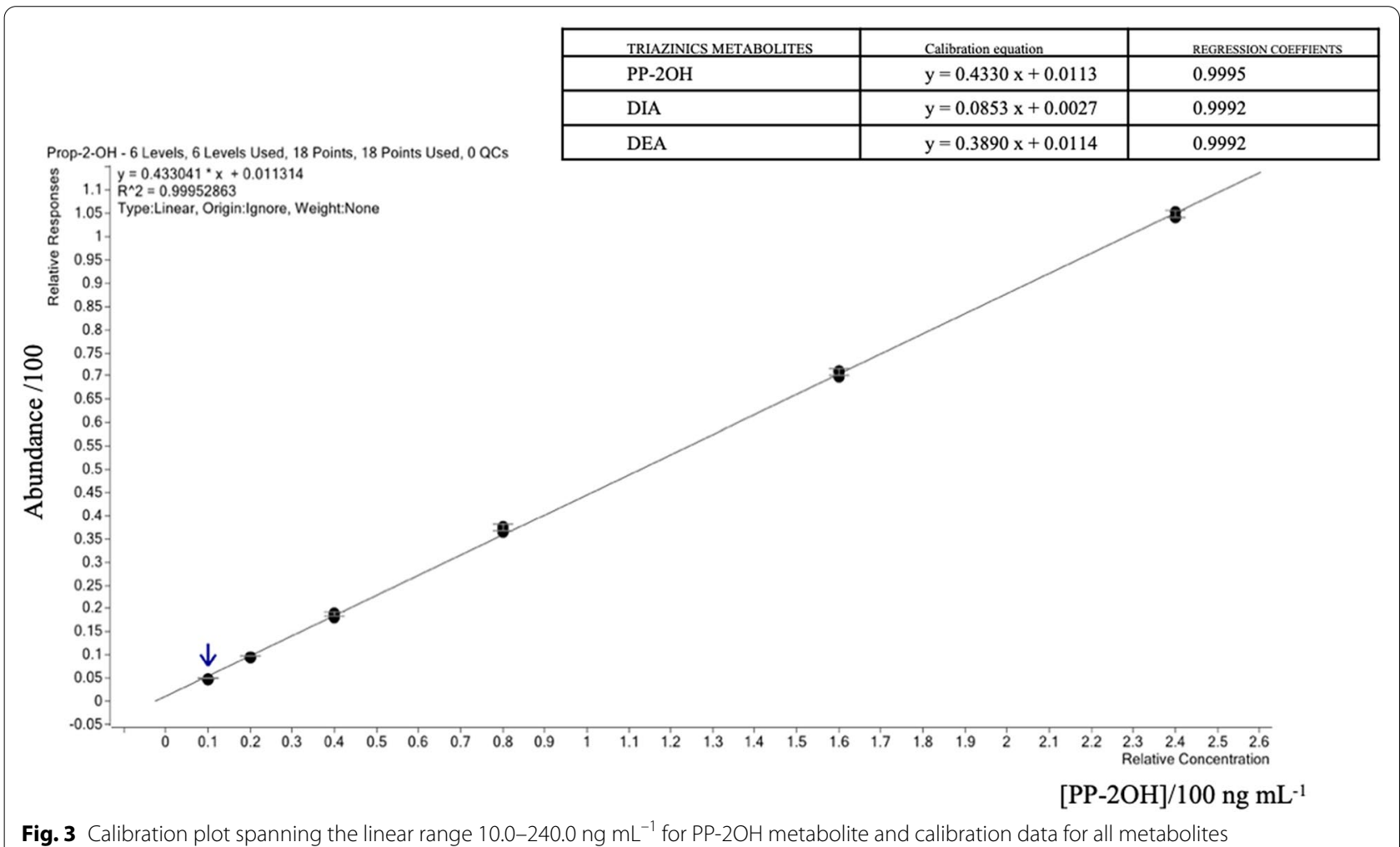

Fig. 3 Calibration plot spanning the linear range $10.0-240.0 \mathrm{ng} \mathrm{mL}^{-1}$ for PP-2OH metabolite and calibration data for all metabolites 
Table 2 Semi-qualitative and quantitative analysis of targeted (DEA, DIA and PP-2OH) and suspected molecules in human semen samples $(n=6)$

\begin{tabular}{|c|c|c|c|c|c|c|}
\hline \multirow[t]{2}{*}{$\begin{array}{l}\text { Samples number } \\
\text { volunteers }\end{array}$} & \multicolumn{3}{|c|}{ Target metabolites $\left(\mathrm{ng} \mathrm{mL}^{-1}\right)$} & \multicolumn{3}{|c|}{$\begin{array}{l}\text { Suspected molecules } \mathrm{RT}(\mathrm{min}) \text {, precursor ion } \\
{[\mathrm{M}+\mathrm{H}]^{+} \text {qualitative transition }}\end{array}$} \\
\hline & DEA & DIA & PP-2OH & PP & Others (s-T) & Unknown \\
\hline 1 & - & - & - & - & $\begin{array}{l}1.5-[146.5]^{+} \\
2.3-[228.0] \\
4.6-[349.9]^{+}\end{array}$ & \\
\hline 2 & - & 9.6 & 11.3 & - & - & ${ }^{*}$ Data not shown \\
\hline 3 & - & - & - & - & - & $1.1-[188 \rightarrow 146]^{+}$ \\
\hline 4 & - & - & 2.7 & $8.50-[231]^{+}$ & - & \\
\hline 5 & - & - & 1.1 & $8.49-[231]^{+}$ & - & \\
\hline 6 & - & - & 8.3 & - & - & $1.2-[188 \rightarrow 146]^{+}$ \\
\hline
\end{tabular}
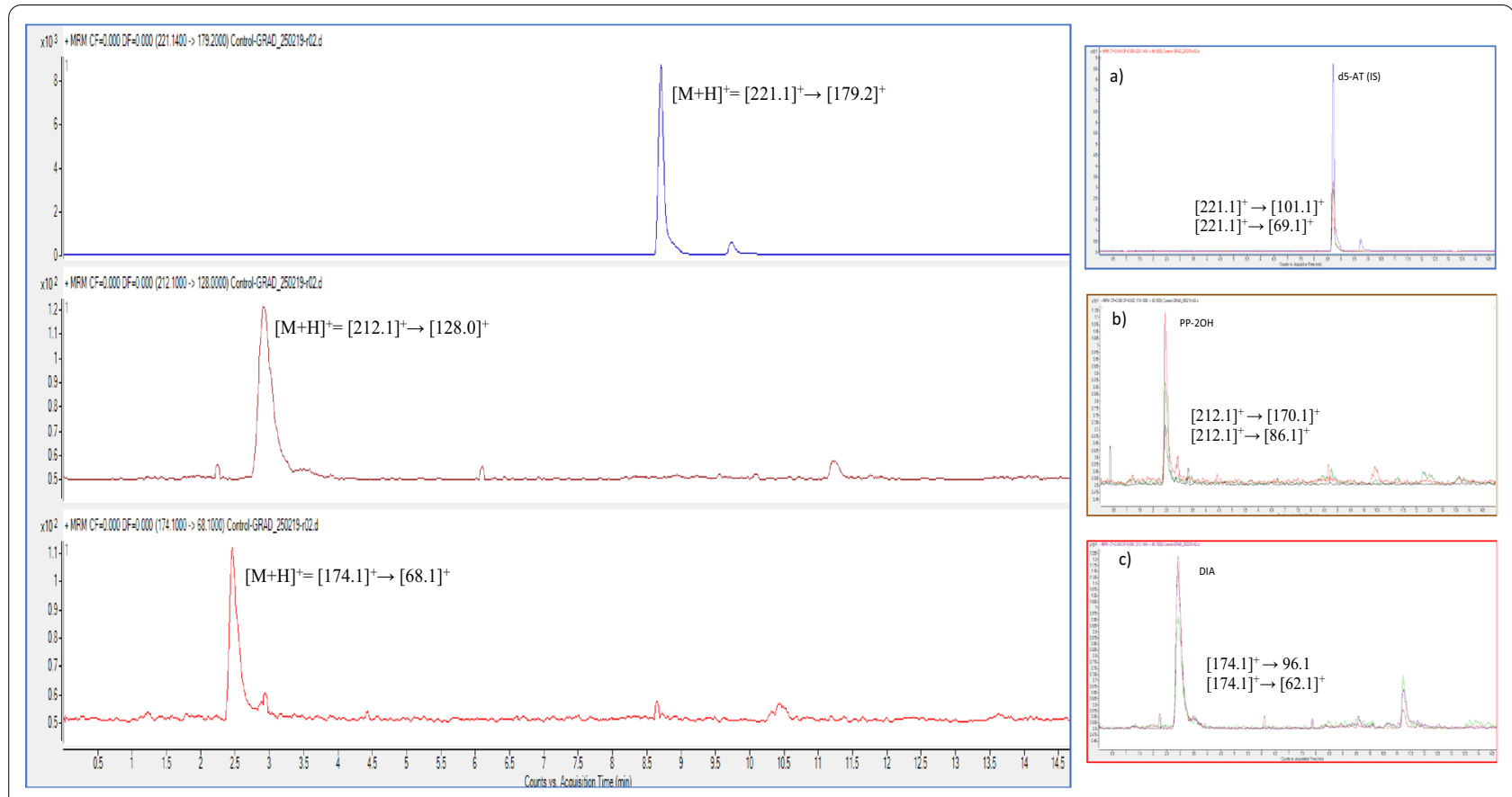

Fig. 4 Extracted ion chromatograms for sample 2 including quantitative and qualitative transitions of a d5-AT (IS), b PP-2OH and c DIA in seminal plasma

$20 \%$. In fact, the other two treatments gave poor recoveries $(<50 \%)$ and were subject to heavy matrix effects. Further validation testing provided RSD values fulfilling the US FDA guidelines for bioanalysis methods.

\section{Analytical quality: precision, $L O D, L O Q$ and linear range}

Precision was assessed as repeatability and reproducibility, both in terms of RSD. Repeatability was estimated from the retention time (RT), absolutes (A) and relative peak areas (RPA) for each analyte by replicate analysis

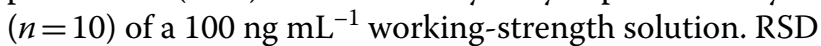

was less than 2 and $4 \%$ for RT, A and RPA, respectively, in all cases.

Within-day and between-day reproducibility were estimated in terms of Snedecor's $F$-value as determined by sequentially injecting 10 freshly prepared samples under identical conditions at 24-h intervals. Differences between variances $\left(S^{2}\right)$ were not significant, so $F_{\exp }$ was less than $F_{\text {tab }}$ for all instrumental variables.

The limits of determination (LOD) and quantification (LOQ) were calculated from replicate analyses $(n=5)$ of working-strength solutions diluted in mobile phase. LOD 
ranged from 150 to $210 \mathrm{pg} \mathrm{mL}^{-1}$ and LOQ from 500 to $700 \mathrm{pg} \mathrm{mL}^{-1}$, both with $\mathrm{RSD}<20 \%$ in all cases.

Linearity in the analytical response was assessed by relating the concentration of each analyte to RPA in tests with mixtures of standards containing $\mathrm{PP}-2 \mathrm{OH}$, DIA and DEA at concentrations from 10 and $240 \mathrm{ng} \mathrm{mL}^{-1}$ in mobile phase and the internal standard at a fixed concentration of $100 \mathrm{ng} \mathrm{mL}^{-1}$. Aliquots $(10 \mu \mathrm{L})$ of these solutions were injected in triplicate into the chromatographic system and processed as described above. Figure 3 shows the equation of the curve for each analyte as determined by least-squares regression and their coefficients.

\section{Application of the proposed method to human semen samples}

The proposed method was applied by determining the analytes in human semen samples. Whole semen samples were previously centrifuged to obtain seminal plasma as described in "Collection of sperm and storage of seminal plasma" Section and then subjected to EH-SPE. Table 2 summarizes the quantitative and semi-qualitative results obtained by subjecting 6 samples to the overall analytical process. MRM was used for targeted analysis and the SCAN mode for untargeted analysis in order to obtain more information and detect other suspected compounds potentially eluted together with the analytes.

$\mathrm{PP}-2 \mathrm{OH}$ metabolite was detected and quantified in four of the six samples, at concentrations from 1.1 to $11.3 \mathrm{ng} \mathrm{mL}^{-1}$. Figure 4 shows the extracted ion chromatograms for sample 2, which allowed the $\mathrm{PP}-2 \mathrm{OH}$ and DIA metabolites to be quantified at a concentration of 11.3 and $9.6 \mathrm{ng} \mathrm{mL}{ }^{-1}$, respectively. These metabolites were unequivocally identified from chromatographic RT and characteristic quantitative and qualitative transitions. Only two of the six samples contained no detectable concentrations of any metabolites (DEA, DIA or PP-2OH).

In other way untargeted analysis in the SCAN mode allowed three different types of ions to be detected as suspected molecules: (a) precursor molecules such as AT and/or PP; (b) other s-triazines and their metabolites (ametrine, prometrine, terbutrine, DACT and DD, among others) and (c) unknown ions. As can be seen from Table 2, all samples contained at least one type of named untargeted compound. Thus, samples 1, 3 and 6 gave several chromatographic peaks for unknown compounds. Also, sample 1 exhibited ions at a RT of 1.53 and $2.26 \mathrm{~min}$ with an $\mathrm{m} / \mathrm{z}$ ratio of 146.0 and 228.0, respectively, for $[\mathrm{M}+\mathrm{H}]^{+}$. These ions could correspond to deethyldeisopropyl atrazine or diamino s-chlorotriazine $\left(\mathrm{mw}=145.5 \mathrm{~g} \mathrm{~mol}^{-1}\right)$ and ametrine $\left(\mathrm{mw} 227.3 \mathrm{~g} \mathrm{~mol}^{-1}\right)$, respectively. Another major ion, [349.9 ${ }^{+}$, was observed at RT of $4.57 \mathrm{~min}$. Samples 3 and 6 gave an identical chromatographic peak with a quantitative transition coinciding with that of DEA metabolite but at different RT (1.2 min). Samples 4 and 5 also gave an identical chromatographic peak with $\mathrm{RT}=8.5 \mathrm{~min}$ and a $m / z$ ratio of 230.7 for the $[\mathrm{M}+\mathrm{H}]^{+}$ion possibly corresponding to propazine $\left(\mathrm{mw}=229.7 \mathrm{~g} \mathrm{~mol}^{-1}\right)$ as it had a higher RT than its metabolite but close to that for deuterated-AT. Both samples were found to contain PP-2OH metabolite at trace levels (1.1-2.7 $\mathrm{ng} \mathrm{mL}^{-1}$ ), which suggests that propazine was still largely in non-metabolized form.

Because it was containing the greatest number of metabolites, sample 2 was subjected to exhaustive untargeted analysis (results not shown). The full-scan chromatogram for this sample included peaks for the most polar ions eluted at a near-zero time $(0.98 \mathrm{~min})$ such as $[104.0]^{+}$and $[197.0]^{+}$, which are chemically similar to those for the targets metabolites at RT of 2.0-3.5 min (viz., $[506.1]^{+}$and $[508.2]^{+}$), in addition to a group of more strongly retained-and hence less polar-ions including $[375.1]^{+},[391.0]^{+}$and $[393.0]^{+}$, with RT similar to those for atrazine and propazine.

After everything discussed above, the proposed method allowed the accurate identification and quantification of targeted and monitoring of untargeted suspected s-triazines potentially associated to sperm viability, mitochondrial activity, oxidative stress and DNA damage. Seminal plasma could be the ideal model sample for further testing with a view to the unequivocal identification of unknown compounds with a high-resolution mass spectrometry detector (e.g., TOF) that may have been previously detected through the use of targeted mass spectrometry detectors (e.g., QQQ).

\section{Conclusions}

A selective, fast analytical method was developed for the simultaneous determination of three atrazine and propazine metabolites (DIA, DEA and PP-2OH) in human seminal plasma by using a deuterated internal standard. The samples were previously subjected to enzymatic hydrolysis (EH) and SPE, and the resulting extract was preconcentrated to obtain recoveries around $90 \%$ with $\mathrm{RSD}<20 \%$. Only $10 \mu \mathrm{L}$ of biological extract was needed to successfully quantify the target analytes at trace (nanogram-per-millilitre) concentration levels by LC/ ESI-MS/MS. Validation procedure confirmed that the proposed method is an accurate, precise, sensitive analytical tool with a broad linearity range for the intended purpose. Application to human semen samples from six donors revealed that the method could be useful to relate the quality of semen to its contents in endocrine disruptors. PP-2OH and DIA were found in four of the six samples studied, at concentrations over the range $1.10-11.3 \mathrm{ng} \mathrm{mL}^{-1}$ and $9.60 \mathrm{ng} \mathrm{mL}^{-1}$, respectively. This result provides for first time potential evidence for the 
bioaccumulation of s-triazine metabolites in humans. Other, suspected compounds and metabolites such as PP, DD, and DACT might have also been present in the samples. Therefore, in order to confirm the results and to conclude on the presence of unknown molecule it will be mandatory to made others studies using high-resolution mass spectrometry detector.

Our optimized, validated analytical method for the qualitative and quantitative determination of triazine metabolites in human seminal plasma may be very useful for practical purposes since their concentration levels in biological fluids may be related to male infertility. The method may therefore open up new avenues for research into the effects of endocrine disruptors present in seminal plasma on various sperm-related parameters-and hence on sperm physiology. Thus, the method could be used to conduct broad-based studies on the potential association of endocrine disruptors and their metabolites in seminal plasma to male infertility, and may thus be useful to examine the impact of sperm physiology on male reproduction function (especially when male fertility is compromised).

To our knowledge, ours is the first method enabling the detection of s-triazine metabolites in seminal plasma, which might be useful with a view to developing effective treatments for male infertility associated to endocrine disruption in the future.

\section{Abbreviations}

LC: Liquid chromatography; MS: Mass spectrometry; LC-ESI: Liquid chromatography-electrospray ionization; MS/MS: Mass spectrometry; QQQ: Triple quadrupole; EDC: Endocrine disrupting chemical; RSD: Relative standard deviation.

\section{Acknowledgements}

The authors thank the Bernabeu Institute for its collaboration in this work and for allowing the collection of the seminal plasma samples.

\section{Authors' contributions}

VRR has contributed to the conception and design of the work and has drafted the work. VRR, AV and AG-C have participated to the acquisition and analysis of data. NV-G and CG-C have contributed to the analysis and interpretation of data. LLM has provided the human samples and contributed to the acquisition and analysis of data. JJG and MRF-S have participates to the conception of the research and approved the submitted version and substantively revised the work. All authors read and approved the final manuscript.
\end{abstract}

\section{Funding}

The authors thank the financial support given by the 01110 AB025 I+D + $\mathrm{i}$ research project given by the Diputación de Albacete and was also funded by the financial support given by the University of Castilla-La Mancha, Spain. The authors have no other relevant affiliations or financial involvement with any organization or entity with a financial interest in or financial conflict with the subject matter or materials discussed in the manuscript apart from those disclosed. No writing assistance was utilized in the production of this manuscript. Ministerio de Ciencia, Innovación y Universidades.

\section{Availability of data and materials}

The data presented in this study are available on request from the corresponding author.

\section{Declarations}

\section{Ethics approval and consent to participate}

The manuscripts reporting studies involving human participants and human sample (whole semen and seminal plasma) a statement on ethic approval and consent by meant Bernabeu Institute, has been include.

\section{Consent for publication}

Not applicable.

\section{Competing interests}

The author declares that they have no competing interests.

\section{Author details}

${ }^{1}$ Faculty of Pharmacy, Regional Center for Biomedical Research, University of Castilla-La Mancha, Albacete, Spain. ${ }^{2}$ Department of Analytical Chemistry and Food Technologies, University of Castilla-La Mancha, Ciudad Real, Spain. ${ }^{3}$ Department of Reproductive Medicine, Instituto Bernabeu, Alicante, Spain. ${ }^{4}$ Cellular Neuroanatomy and Molecular Chemistry of the Central Nervous System, SaBio IREC (CSIC-UCLM-JCCM), Ciudad Real, Spain.

Received: 3 November 2021 Accepted: 12 January 2022

Published online: 22 February 2022

\section{References}

1. Selvaraju V, Baskaran S, Agarwal A, Henkel R. Environmental contaminants and male infertility: effects and mechanisms. Andrologia. 2020;53:e13646.

2. Diamanti-Kandarakis E, Bourguignon JP, Giudice LC, Hauser R, Prins GS, Soto AM, Zoeller RT, Gore AC. Endocrine-disrupting chemicals: an Endocrine Society scientific statement. Endocr Rev. 2009;30:293-342.

3. U.J.d.b.t.O.o.C.S.P.P.a.t.O.o.W. Environmental Protection Agency, U.S. Environmental Protection Agency Endocrine Disruptor Screening Program Comprehensive Management Plans. 2014. https://www.epa.gov/endoc rine-disruption/endocrine-disruptor-screening-program-edsp-compr ehensive-management-plans.

4. World Health Organization, United Nations Environment Programme, Inter-Organization Programme for the Sound Management of Chemicals, Bergman, Åke, Heindel, Jerrold J et al (2013) State of the science of endocrine disrupting chemicals 2012: summary for decision-makers. World Health Organization. https://apps.who.int/iris/handle/10665/78102.

5. Jurewicz J, Radwan M, Sobala W, Radwan P, Jakubowski L, Wielgomas B, Ligocka D, Brzeźnicki S, Hanke W. Exposure to widespread environmental endocrine disrupting chemicals and human sperm sex ratio. Environ Pollut. 2016;213:732-40.

6. Jiang H, Adams C, Graziano N, Roberson A, McGuire M, Khiari D. Occurrence and removal of chloro-s-triazines in water treatment plants. Environ Sci Technol. 2006:40:3609-16.

7. Atwood D, Paisley-Jones C (2017) Pesticides industry sales and usage: 2008-2012 market estimates. US Environmental Protection Agency, Washington, DC, 2017; vol 20460. https://www.epa.gov/sites/default/ files/2017-01/documents/pesticides-industry-sales-usage-2016_0.pdf.

8. Brandhonneur N, Hutin V, Chevrier C, Cordier S, Le Corre P. Maternal and fetal blood pharmacokinetics and organ distribution of atrazine, propazine, simazine, and their metabolites in pregnant rats after chronic oral administration. Toxicol Sci. 2020;173:255-66.

9. Sawunyama P, Bailey GW. Computational chemistry study of the environmentally important acid-catalyzed hydrolysis of atrazine and related 2-chloro-s-triazines. Pest Manag Sci. 2002;58:759-68.

10. Schmitt P, Garrison AW, Freitag D, Kettrup A. Separation of s-triazine herbicides and their metabolites by capillary zone electrophoresis as a function of pH. J Chromatogr A. 1996;723:169-77.

11. Schmitt P, Freitag D, Sanlaville Y, Lintelmann J, Kettrup A. Capillary electrophoretic study of atrazine photolysis. J Chromatogr A. 1995;709:215-25.

12. Abian J, Durand G, Barcelo D. Analysis of chlorotriazines and their degradation products in environmental samples by selecting various operating modes in thermospray HPLC/MS/MS. J Agric Food Chem. 1993:41:1264-73 
13. Rodríguez-González N, Uzal-Varela R, González-Castro MJ, MuniateguiLorenzo S, Beceiro-González E. Reliable methods for determination of triazine herbicides and their degradation products in seawater and marine sediments using liquid chromatography-tandem mass spectrometry. Environ Sci Pollut Res Int. 2017;24:7764-75.

14. Drobnis EZ, Nangia AK. Male reproductive functions disrupted by pharmacological agents. Impacts of medications on male fertility, Springer International Publishing, USA. Adv Exp Med Biol. 2017;1034(13):13-24.

15. Komsky-Elbaz A, Zubov A, Roth Z. Effect of the herbicide atrazine and its major metabolite, DACT, on bovine sperm cryotolerance. Theriogenology. 2019;140:117-23.

16. Hanioka N, Jinno H, Tanaka-Kagawa T, Nishimura T, Ando M. In vitro metabolism of simazine, atrazine and propazine by hepatic cytochrome P450 enzymes of rat, mouse and guinea pig, and oestrogenic activity of chlorotriazines and their main metabolites. Xenobiotica. 1999:29:1213-26.

17. Adams NH, Levi PE, Hodgson E. In vitro studies of the metabolism of atrazine, simazine, and terbutryn in several vertebrate species. J Agric Food Chem. 1990;38(6):1411-7.

18. Hanioka N, Jinno H, Tanaka-Kagawa T, Nishimura T, Ando M. In Vitro Metabolism of chlorotriazines: characterization of simazine, atrazine, and propazine metabolism using liver microsomes from rats treated with various cytochrome P450 inducers. Toxicol Appl Pharmacol. 1999;156:195-205.

19. McMullin TS, Andersen ME, Tessari JD, Cranmer B, Hanneman WH. Estimating constants for metabolism of atrazine in freshly isolated rat hepatocytes by kinetic modeling. Toxicol In Vitro. 2007;21:492-501.

20. Brzezicki JM, Andersen ME, Cranmer BK, Tessari JD. Quantitative identification of atrazine and its chlorinated metabolites in plasma. J Anal Toxicol. 2003;27:569-73.

21. Lang D, Criegee D, Grothusen A, Saalfrank RW, Böcker RH. In vitro metabolism of atrazine, terbuthylazine, ametryne, and terbutryne in rats, pigs, and humans. Drug Metab Dispos. 1996;24:859-65.

22. Barr DB, Panuwet P, Nguyen JV, Udunka S, Needham LL. Assessing exposure to atrazine and its metabolites using biomonitoring. Environ Health Perspect. 2007;115:1474-8.

23. Timchalk C, Dryzga MD, Langvardt PW, Kastl PE, Osborne DW. Determination of the effect of tridiphane on the pharmacokinetics of [14C]-atrazine following oral administration to male Fischer 344 rats. Toxicology. 1990:61:27-40.

24. Ross MK, Filipov NM. Determination of atrazine and its metabolites in mouse urine and plasma by LC-MS analysis. Anal Biochem. 2006;351:161-73.

25. Nevado JJB, Cabanillas CG, Llerena MJV, Robledo VR. Sensitive SPE GC-MSSIM screening of endocrine-disrupting herbicides and related degradation products in natural surface waters and robustness study. Microchem J. 2007;87:62-71.

26. Van der Hoff GR, Van Zoonen P. Trace analysis of pesticides by gas chromatography. J Chromatogr A. 1999;843:301-22.

27. Pitarch E, Cervera MI, Portolés T, Ibáñez M, Barreda M, Renau-Pruñonosa A, Morell I, López F, Albarrán F, Hernández F. Comprehensive monitoring of organic micro-pollutants in surface and groundwater in the surrounding of a solid-waste treatment plant of Castellón, Spain. Sci Total Environ. 2016;548-549:211-20

28. Fonseca E, Renau-Pruñonosa A, Ibáñez M, Gracia-Lor E, Estrela T, Jiménez S, Pérez-Martín MÁ, González F, Hernández F, Morell I. Investigation of pesticides and their transformation products in the Júcar River Hydrographical Basin (Spain) by wide-scope high-resolution mass spectrometry screening. Environ Res. 2019;177:108570.

29. Di Venere M, Viglio S, Cagnone M, Bardoni A, Salvini R, ladarola P. Advances in the analysis of "less-conventional" human body fluids: an overview of the CE- and HPLC-MS applications in the years 2015-2017. Electrophoresis. 2018;39:160-78.

30. Swan SH. Semen quality in fertile US men in relation to geographical area and pesticide exposure. Int J Androl. 2006;29:62-8.

31. León Z, Chisvert A, Tarazona I, Salvador A. Solid-phase extraction liquid chromatography-tandem mass spectrometry analytical method for the determination of 2-hydroxy-4-methoxybenzophenone and its metabolites in both human urine and semen. Anal Bioanal Chem 2010;398:831-43.
32. Gilany K, Minai-Tehrani A, Savadi-Shiraz E, Rezadoost H, Lakpour N. Exploring the human seminal plasma proteome: an unexplored gold mine of biomarker for male infertility and male reproduction disorder. J Reprod Infertil. 2015;16:61-71.

33. Gilany K, Moazeni-Pourasil RS, Jafarzadeh N, Savadi-Shiraz E. Metabolomics fingerprinting of the human seminal plasma of asthenozoospermic patients. Mol Reprod Dev. 2014;81:84-6.

34. Samanta L, Parida R, Dias TR, Agarwal A. The enigmatic seminal plasma: a proteomics insight from ejaculation to fertilization. Reprod Biol Endocrinol. 2018;16:41.

35. Sharma R, Agarwal A, Mohanty G, Jesudasan R, Gopalan B, Willard B, Yadav SP, Sabanegh E. Functional proteomic analysis of seminal plasma proteins in men with various semen parameters. Reprod Biol Endocrinol. 2013;11:38.

36. Engel KM, Baumann S, Rolle-Kampczyk U, Schiller J, von Bergen M, Grunewald S. Metabolomic profiling reveals correlations between spermiogram parameters and the metabolites present in human spermatozoa and seminal plasma. PLoS ONE. 2019;14:e0211679.

37. Tavalieri YE, Galoppo GH, Canesini G, Luque EH, Muñoz-de-Toro MM. Effects of agricultural pesticides on the reproductive system of aquatic wildlife species, with crocodilians as sentinel species. Mol Cell Endocrinol. 2020;518:110918.

38. Hase Y, Tatsuno M, Nishi T, Kataoka K, Kabe Y, Yamaguchi Y, Ozawa N, Natori M, Handa H, Watanabe H. Atrazine binds to F1FO-ATP synthase and inhibits mitochondrial function in sperm. Biochem Biophys Res Commun 2008;366:66-72.

39. Abu-Awwad A, Arafat T, Schmitz OJ. Simultaneous determination of nicotine, cotinine, and nicotine $\mathrm{N}$-oxide in human plasma, semen, and sperm by LC-Orbitrap MS. Anal Bioanal Chem. 2016;408:6473-81.

40. Imaz A, Niubó J, Kashuba A, Ferrer E, Sykes C, Rozas N, Acerete L, Vila A, Podzamczer D. Elvitegravir concentrations in seminal plasma in HIV1-infected men. HIV Med. 2017;18:225-30.

41. Ma B, Shang X, Zhang Q, Li J, Liu Y, Cao X, Xu Q. Rapid analysis of tadalafil in human blood plasma and seminal plasma by liquid chromatography/ tandem mass spectrometry. J Pharm Biomed Anal. 2013;77:149-57.

42. Vitku J, Chlupacova T, Sosvorova L, Hampl R, Hill M, Heracek J, Bicikova M, Starka L. Development and validation of LC-MS/MS method for quantification of bisphenol A and estrogens in human plasma and seminal fluid. Talanta. 2015;140:62-7.

43. Vitku J, Heracek J, Sosvorova L, Hampl R, Chlupacova T, Hill M, Sobotka $\checkmark$, Bicikova M, Starka L. Associations of bisphenol A and polychlorinated biphenyls with spermatogenesis and steroidogenesis in two biological fluids from men attending an infertility clinic. Environ Int. 2016:89-90:166-73.

44. Vitku J, Sosvorova L, Chlupacova T, Hampl R, Hill M, Sobotka V, Heracek J, Bicikova M, Starka L. Differences in bisphenol A and estrogen levels in the plasma and seminal plasma of men with different degrees of infertility. Physiol Res. 2015;64:S303-311.

45. You L, Wang YX, Zeng Q, Li M, Huang YH, Hu Y, Cao WC, Liu AL, Lu WQ. Semen phthalate metabolites, spermatozoa apoptosis, and DNA damage: a cross-sectional study in China. Environ Sci Technol. 2015;49:3805-12.

46. Crisp TM, Clegg ED, Cooper RL, Wood WP, Anderson DG, Baetcke KP, Hoffmann JL, Morrow MS, Rodier DJ, Schaeffer JE, Touart LW, Zeeman MG, Patel YM. Environmental endocrine disruption: an effects assessment and analysis. Environ Health Perspect. 1998;106(Suppl 1):11-56.

\section{Publisher's Note}

Springer Nature remains neutral with regard to jurisdictional claims in published maps and institutional affiliations. 